\title{
Evaluation of Antioxidant Activity of Apple Peel and Pulp Extracts by Using Different Solvents
}

\author{
RAVI KUMAR GOUR and PRASHANT ANTHONY
}

Department of Chemistry, School of Basic Sciences Sam Higginbottom Institute of Agriculture, Technology \& Sciences (Deemed-to-be-University) Allahabad -211007, India jaigour90@gmail.com

Received 5 March 2015 / Accepted 18 March 2015

\begin{abstract}
Evaluation of antioxidant activity of apple peel and pulp extracts by using different solvents was studied. Apple variety used for extraction was Gala. Apple peel and pulp extracts were prepared by using methanol, chloroform: acetone (4:1) and ethyl acetate solvents. The antioxidant activities of these extracts were determined by DPPH (1, 1- Diphenyl - 2- picryl hydroxyl) assay and RPA (reducing power assay) method. On comparing the activities of peel and pulp it was found that the activity of peel extracts was higher. It was found that free radical scavenging activity of both apple peel and pulp crude extracts was significantly higher in methanol extract among all the extracts studied. Reducing power assay (RPA) also gave significant results with methanol extract. All the extracts showed lower antioxidant activity compared to Gallic acid when used as standard.
\end{abstract}

Keywords: DPPH - (1, 1- Diphenyl - 2- picrylhydrazyl) assay, Reducing power assay, Antioxidant activity, Apple peel and pulp

\section{Introduction}

Fruits and vegetables contain high antioxidant which is beneficial for our health. In recent years, a wide variety of fruit products with beneficial health effects have been developed and marketed. However, only limited information on the nutritional value and bioactive compounds of tropical fruits, especially the more exotic species is currently available ${ }^{1}$.

One of the examples of fruit that contains high antioxidant contents is apple (malus domestica). It is important source of flavonoids and phenols which is consumed by us whole year. Consumption of apples has been linked with the prevention of chronic diseases and with a lower incidence of cancer ${ }^{2}$. Apple consumption has also been associated with a decreased risk of coronary heart disease in women ${ }^{3}$. Apples contain many types of phenolic derivates and flavonoids. Moreover, the concentration of phenolic compounds may be affected by apple variety, cultivar and genus and also by extrinsic factors, such as soil, seasonality, agronomic factors, light exposure, $e t c^{4}$. Apple polyphenols have various in vitro 
bioactivities, possibly in combination with dietary fibre (i.e. reduced risk of coronary heart disease $)^{5}$. It is highly beneficial for our health due to its medicinal properties that act against diseases associated with oxidation and anti-aging ${ }^{6}$.

Recent studies has confirmed that the unripe apples along with its seeds and peels are a great source of polyphenols ${ }^{7}$. Free radicals are normally generated in substantial amounts as a by-product of various internal metabolic processes in aerobic organisms such as phagocytosis, neutrophiles defence, auto oxidation of catecholamine and carboxylation or hydroxylation reactions. These free radicals are neutralized by antioxidants, as a result it prevents the oxidative stress that may lead to oxidation related diseases ${ }^{8}$.

Anthocyanins pigments belong to the group of flavonoids has attracted great interest due to the wide biological activities, including its antioxidant, anti-inflammatory and anticarcinogenic properties ${ }^{9}$. There is higher amount of phenolic compounds and ascorbic acids in the peel than in the pulp for most of the fruits ${ }^{10}$. The skin usually contains higher bioactive compounds in order to protect the inner materials from insects and microorganisms ${ }^{11}$. Therefore the objective of this study was to compare antioxidant activity of apple peel and pulp extracts by DPPH and Reducing power assay method.

\section{Experimental}

Ethanol, methanol, chloroform, acetone and ethyl acetate, DPPH, potassium ferricynide, trichloro acetic acid and ferric chloride used were of Merck and Loba fine.

\section{Sample preparation}

The apple fruits were collected from the local market of Allahabad. Apples were washed, separated into pulps and peels and sliced into small pieces. The sample was oven dried at 50- $60{ }^{\circ} \mathrm{C}$ to constant weight ${ }^{12}$.

\section{Prepation of extracts}

Apple peel and pulp extracts were prepared by the Soxhlet method ${ }^{13} .25 \mathrm{~g}$ of dried peel and $45 \mathrm{~g}$ of dried pulp sample were taken in soxhlet for different solvents [methanol, chloroform: acetone (4:1)] and ethyl acetate] and the extraction was carried out twice for $8 \mathrm{~h}$ at $60{ }^{\circ} \mathrm{C}$ separately. The solvents in the extracts were removed using distillation unit at $40{ }^{\circ} \mathrm{C}$. The standard extracts were obtained and sealed with aluminum foils and stored in the refrigerator at $4{ }^{\circ} \mathrm{C}$ until required for Antioxidant activity.

\section{$D P P H$ free radical scavenging assay}

The hydrogen atom or electron donation capacity of the extracts was measured as a decrease in absorbance of DPPH. The scavenging ability of apple peel and pulp extracts were determined based on the method given by Yamaguchi ${ }^{14}$. The reaction between antioxidant compounds with the stable DPPH radical will caused reduction in absorbance and decolourisation of DPPH to light yellow ${ }^{14}$. To $1.5 \mathrm{~mL}$ of methanolic DPPH solution $(0.1 \mathrm{mM})$ was introduced varying concentrations of the extract in methanol $[0.1 \mathrm{mg} / \mathrm{mL}(100 \mu \mathrm{gm} / \mathrm{mL})-5.0 \mathrm{mg} / \mathrm{mL}$ $(5000 \mu \mathrm{gm} / \mathrm{mL})]$. A control sample was prepared without extract containing DPPH solution in a appropriate volume. Methanol was used as a blank. The mixtures obtained were shaken well and left for 20 minutes at room temperature and the absorbance of the resulting solutions were taken at $517 \mathrm{~nm}$ against a blank in UV visible spectrophotometer. The radical scavenging activity was measured as a decrease in the absorbance of DPPH.

$$
\% \text { scavenging activity }=1-\frac{\text { Abs sample } \times 100}{\text { Abs Control }}
$$




\section{Reducing power assay}

In this assay, $\mathrm{Fe}^{3+} /$ ferricyanide complex is reduced to the ferrous form by antioxidants. The $\mathrm{Fe}^{2+}$ formed is monitored by measuring the formation of Prussian blue colour at $700 \mathrm{~nm}^{15}$. Different concentrations of extract $(200,400,600$ and $800 \mu \mathrm{g} / \mathrm{mL})$ were mixed with $2.5 \mathrm{~mL}$ of phosphate buffer and $2.5 \mathrm{~mL}$ of potassium ferricyanide $\left[\mathrm{K}_{3} \mathrm{Fe}(\mathrm{CN})_{6}\right]$ in test tubes. The mixture was incubated for $20 \mathrm{~min}$ at $50{ }^{\circ} \mathrm{C}$. At the end of the incubation $2.5 \mathrm{~mL}$ of tri-chloroacetic acid was added to the mixtures followed by centrifuging at $500 \mathrm{rpm}$ for $10 \mathrm{~min}$. The upper layers $(2.5 \mathrm{~mL})$ were then mixed in $2.5 \mathrm{~mL}$ distilled water and $0.5 \mathrm{~mL}$ of ferric chloride and the absorbance was measured at $700 \mathrm{~nm}$. The reducing power tests were done in triplicates. Increase in absorbance of the reaction mixture indicated the reducing power of sample.

\section{Results and Discussion}

The DPPH free radical scavenging activity and reducing power activity of apple peel and pulp extracts were determined for different solvents (methanol, chloroform: acetone (4:1) and ethyl acetate). Gallic acid was taken as standard.

The results in Table 1 and Figure 1 reveal that percent inhibition increases with increasing concentration of extract whereasTable 2 and Figure 2 reveal that reducing power activity of extract increases with increase in concentration.

Table 1. DPPH Free radical scavenging activity of peel and pulp extracts of apple

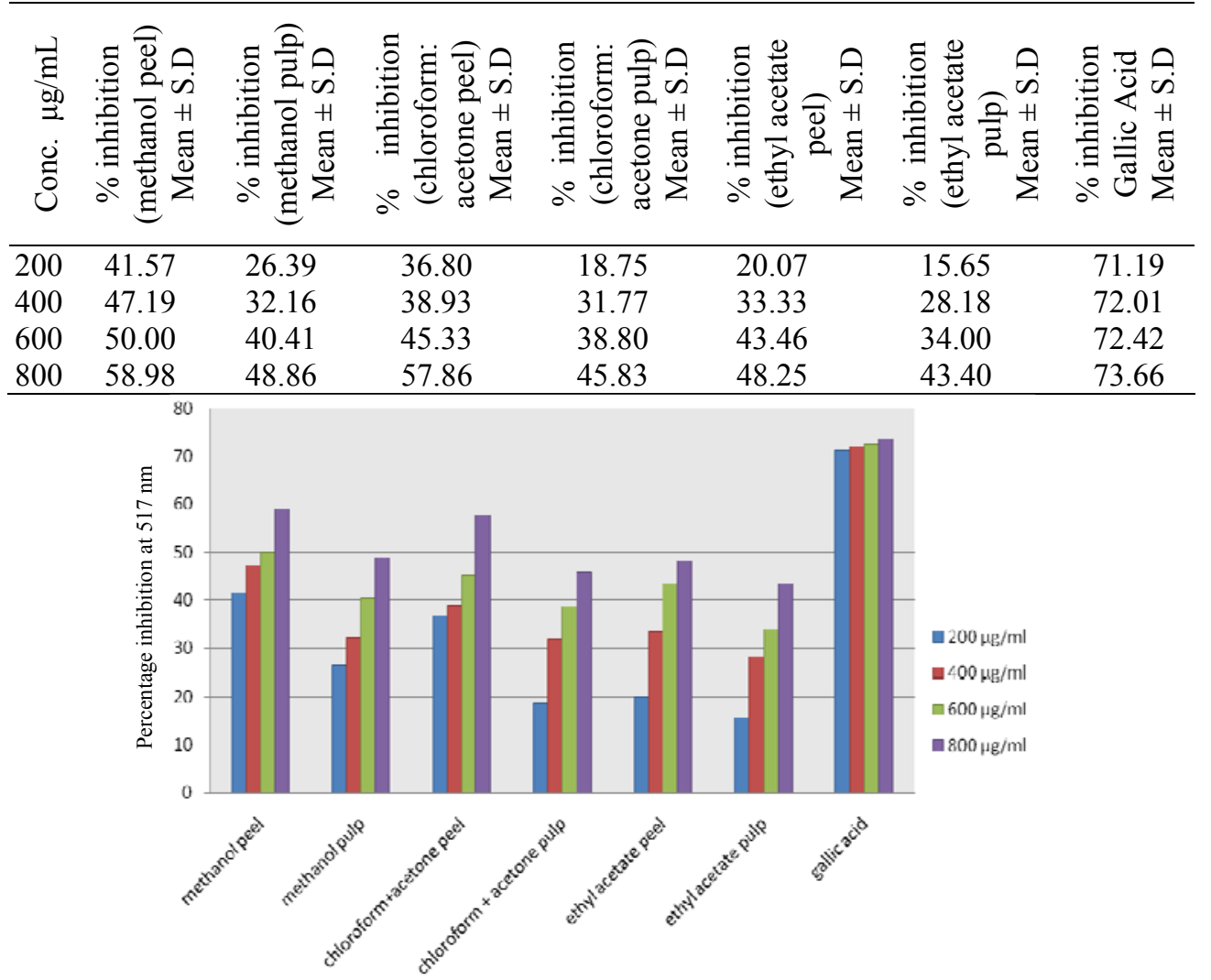

Figure 1. DPPH Free radical scavenging activity of peel and pulp extracts of apple 
Table 2. Reducing Power Activity of peel and pulp extracts of apple

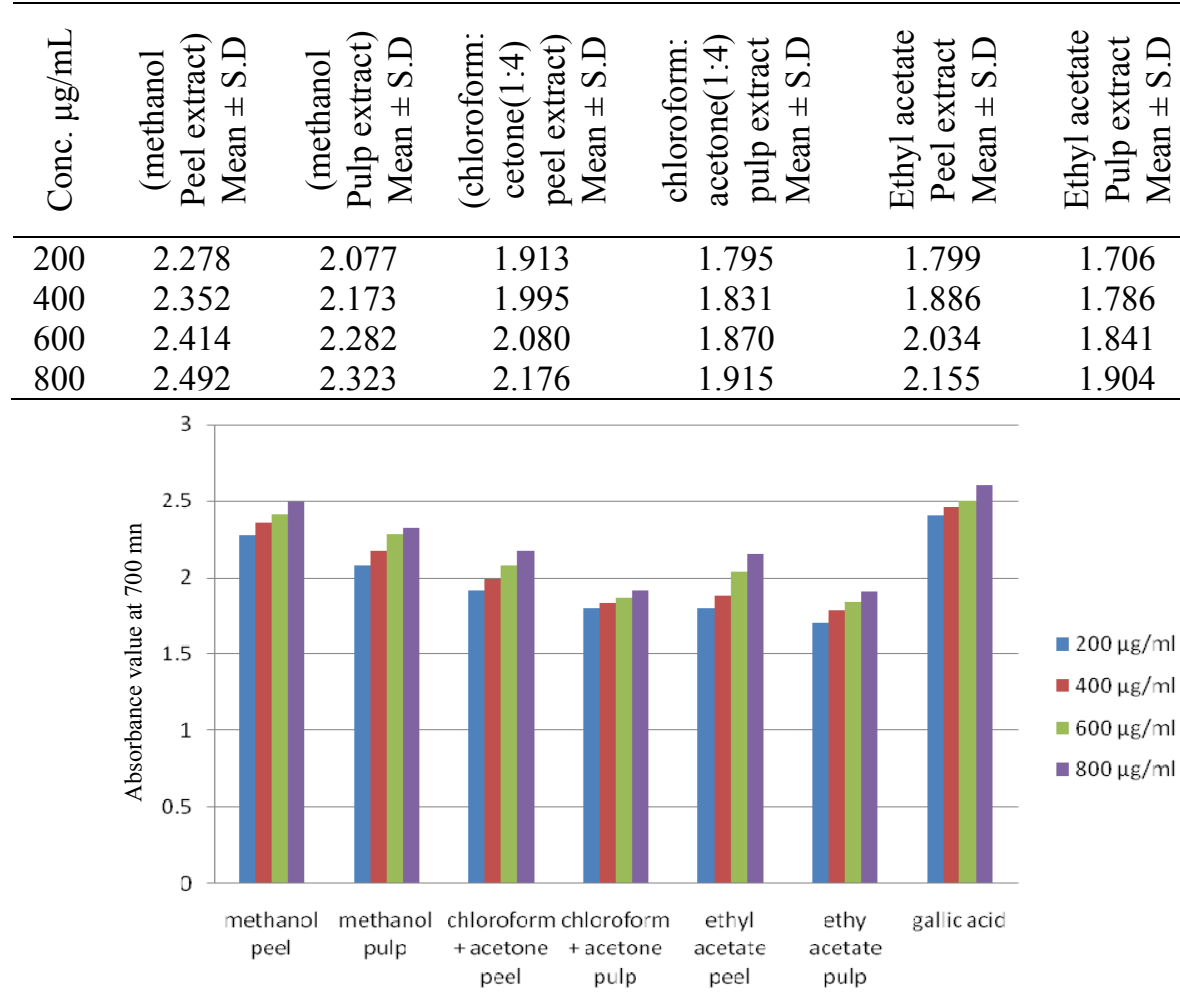

Figure 2. Reducing Power Activity of peel and pulp extracts of apple

Among extracts peel extracts showed higher antioxidant and reducing activity than pulp extracts. This may be due to the presence of different antioxidant compound viz. apple pulp viz. catechin, procyanidin, caffeic acid and chlorogenic acid whereas the peel contains aforementioned substances as well as flavonoids, not present in pulp, such as quercetin glycosides and cyanidin glycosides which makes peels more effective than pulp ${ }^{16}$.

While among the different solvent extracts the high antioxidant and reducing activity was measured in methanol extract of apple. The extract obtained from polar solvents had higher concentrations of phenol while the extracts obtained from low polar solvents were found to have small concentrations ${ }^{17}$.

\section{Summary and Conclusion}

The dried peel and pulp sample of Malus domestica were extracted using three solvents methanol, chloroform: acetone (4:1) and ethyl acetate. Antioxidant activity was taken by using two methods DPPH free radical scavenging activity and reducing power assay method. It was also observed that the two methods (DPPH free radical scavenging activity and reducing power assay) showed similar trends in antioxidant activity for a particular extract.

Further, the potential of apples must be explored more and more, in order to develop an alternate therapy for the treatment of infections caused by free radicals and microorganisms Bacteria and the present study also suggest that this apple may be exploited for health supplement. 


\section{References}

1. Botero M, Ricaurte S, Monsalve C and Rojano B, Scientia Technicals, 2007, 13, 295-296.

2. Jakopic J, Stampar F and Veberic R, Scientific Horticulture, 2009, 123(2), 234-239; DOI:10.1016/j.scienta.2009.09.004

3. Sesso H D, Gaziano J M, Liu S and Buring J E, Am J Clin Nutri., 2003, 77, 14001408 .

4. Vieira F G K, Da Silva G, Copetti C, Faria P, Da Costa E and Fett R, Scientia Horticulturae, 2011, 128(3), 261-266; DOI:10.1016/j.scienta.2011.01.032

5. Boyer J and Liu R H, Nutri., J, 2007, 3, 5-20.

6. Balboa E M, Conde E, Moure A, Falqué E and Domínguez H, Food Chem., 2013, 138(2-3), 1764-1785; DOI:10.1016/j.foodchem.2012.11.026

7. Chodak D A, Tarko T, Satora P, Sroka P and Tuszyński T, J Fruit Orna Plant Res., 2010, 18 (2), 39-50.

8. Bamoniri A, Haghir E A, Mazoochi A, Behpour M, Jookar K F and Batooli H, Food Chem., 2010, 122(3), 553-558; DOI:10.1016/j.foodchem.2010.03.009

9. Santos D T, Albarelli J Q, Beppu M M and Meireles M A A, Food Res Int., 2013, 50(2), 617-624; DOI:10.1016/j.foodres.2011.04.019

10. Gorinstein S, Zachwieja Z, Katrich E, Pawelzik E, Haruenkit R, Trakhtenberg S and Martin B O, Food Sci Technol., 2004, 37(3), 337-343;

DOI:10.1016/j.lwt.2003.10.005

11. Jeong S M, Kim S Y, Kim D R, Jo S C, Nam K C, Ahn D U and Lee S C, J Agr Food Chem., 2004, 52(11), 3389-3393; DOI:10.1021/jf049899k

12. Duh P D, Tu Y Y and Yen G C, Lebensmittel-Wissenschaft Technology, 1999, 32(5), 269-277; DOI:10.1006/fstl.1999.0548

13. Jayaprakasha G K, Selvi T and Sakaria K K, Food Res Int., 2003, 36(2), 117 -122; DOI:10.1016/S0963-9969(02)00116-3

14. Yamaguchi T, Takamura H, Matoba T and Terao J, Biosci Biotechnol Biochem., 1998, 62(6), 1201-1204; DOI:10.1271/bbb.62.1201

15. Yildirim A, Mavi A and Kara A A, J Agr Food Chem., 2001, 49(8), 4083-4089; DOI:10.1021/jf0103572

16. Manzoor M, Anwar F, Saari N and Ashraf M, Molecules, 2012, 17(1), 390-407; DOI:10.3390/molecules17010390

17. Doss A and Pungalenthi M, J Pharmaceutical Scientific Innovation, 2012, 1(3), 1- 4. 